This item was submitted to Loughborough's Research Repository by the author.

Items in Figshare are protected by copyright, with all rights reserved, unless otherwise indicated.

\title{
Initiation of the cadmium chloride assisted re-crystallization process of magnetron sputtered thin film CdTe
}

PLEASE CITE THE PUBLISHED VERSION

https://doi.org/10.1109/pvsc.2013.6744847

PUBLISHER

IEEE

VERSION

AM (Accepted Manuscript)

\section{PUBLISHER STATEMENT}

Personal use of this material is permitted. Permission from IEEE must be obtained for all other uses, in any current or future media, including reprinting/republishing this material for advertising or promotional purposes, creating new collective works, for resale or redistribution to servers or lists, or reuse of any copyrighted component of this work in other works.

\section{LICENCE}

\section{All Rights Reserved}

\section{REPOSITORY RECORD}

Abbas, Ali, Bianca Maniscalco, Jake Bowers, Piotr Kaminski, Geoff West, and Michael Walls. 2014. "Initiation of the Cadmium Chloride Assisted Re-crystallization Process of Magnetron Sputtered Thin Film Cdte". Loughborough University. https://hdl.handle.net/2134/12783230.v1. 


\title{
Initiation Of The Cadmium Chloride Assisted Re-Crystallization Process Of Magnetron Sputtered Thin Film CdTe
}

\author{
A. Abbas ${ }^{1}$, B. Maniscalco ${ }^{1}$, J.W. Bowers ${ }^{1}$, P.M. Kaminski ${ }^{1}$, G.D. West ${ }^{2}$ and J.M. Walls ${ }^{1}$ \\ ${ }^{1}$ Centre for Renewable Energy Systems Technology, (CREST), School of Electronic, Electrical and \\ Systems Engineering, Loughborough University, Leicestershire, LE11 3TU, UK \\ ${ }^{2}$ Department of Materials, Loughborough University, Leicestershire, LE11 3TU, UK
}

\begin{abstract}
The re-crystallization of thin film cadmium telluride (CdTe) using the cadmium chloride $\left(\mathrm{CdCl}_{2}\right)$ annealing procedure is a vital process for obtaining high efficiency photovoltaic devices. Although the process is crucial, the precise micro-structural mechanisms at work are poorly understood. Recently it has been observed that untreated CdTe contains a high density of stacking faults and that these are removed in the $\mathrm{CdCl}_{2}$ assisted re-crystallization. In this paper, we report on experiments using magnetron sputtered CdTe to determine the effects of the re-crystallization process. In particular, we have focused on how the re-crystallization process initiates by using ultra-low concentrations of $\mathrm{CdCl}_{2} \quad(0.06 \%$ and $\mathbf{0 . 0 3 \%}$ of saturated $\mathbf{C d C l}_{2}$ in methanol). With these low concentrations a partial re-crystallization occurs, with the initiation occurring at the $\mathrm{CdS} / \mathrm{CdTe}$ interface and not at the surface of the CdTe layer.
\end{abstract}

Index Terms - Thin films, Photovoltaic Cell, Cadmium Telluride, Cadmium Chloride, Sputtering, Scanning Electron Microscopy, Transmission Electron Microscopy.

\section{INTRODUCTION}

Thin film cadmium telluride (CdTe) solar modules are currently the most commercially important thin film technology as judged by overall production levels [1]. Modules are manufactured on an industrial scale with low-cost production. They can be manufactured in less than 2.5 hours in a continuous and automated process. Module efficiency is lower than that achieved with $\mathrm{c}-\mathrm{Si}$, but both module and champion cell efficiencies have recently increased markedly. The record cell efficiency is now $18.7 \%$ and the record reported for module efficiency is $16.1 \%$ achieved by First Solar Inc. [2]. Despite these recent improvements, these record efficiencies are well short of the theoretical limit and there is still considerable scope for increasing efficiency and thereby reducing the cost of energy produced.

The cadmium chloride $\left(\mathrm{CdCl}_{2}\right)$ assisted re-crystallization of the CdTe layer is a crucial process required to achieve high efficiency. However, despite its importance, the precise microstructural mechanisms at work during the process are still poorly understood. A recent study of CdTe thin films deposited using close space sublimation revealed the presence of high densities of stacking faults [3] [4]. These defects were subsequently eliminated by the $\mathrm{CdCl}_{2}$ assisted recrystallization. These studies were carried out using advanced micro-structural analysis techniques. Samples were prepared using an "in situ" lift out method in a dual beam Focused Ion
Beam-Field Emission Gun Scanning Electron Microscope (FIB-FEG-SEM). Analysis of the detailed microstructure was then performed using Transmission Electron Microscopy (TEM).

In this study, we have used the same advanced microstructural analysis techniques to determine where the recrystallization process starts in the multilayer stack. Initially, we have chosen to use magnetron sputtered CdTe because this material contains narrow columnar grains and the effect of the re-crystallization process is much more pronounced than that observed in close spaced sublimated materials where the grain size is much larger and less affected by the $\mathrm{CdCl}_{2}$ treatment. By creating a better understanding of the processes that leads to increased efficiency, it may be possible to improve the process and further increase their effectiveness and subsequent device performance.

\section{EXPERIMENTAL}

\section{A. Sputtered CdS/CdTe Solar Cells}

Thin films of CdS and CdTe were deposited by pulsed DC magnetron sputtering. The system used has been described previously [5]. The system is equipped with four linear magnetrons with each adjacent magnetron configured with opposite polarity to create a closed magnetic field to enhance the plasma density to $\sim 5 \mathrm{~mA} / \mathrm{cm}^{2}$ [6] [7]. The deposition energy is determined by the induced Voltage on the electrically isolated substrate carrier which is typically in the range $25 \mathrm{~V}$ to $50 \mathrm{~V}$. The magnetrons and substrate holder are vertically mounted around a cylindrical vacuum chamber to avoid particulate contamination. The substrate carrier rotates so that the different layers can be deposited sequentially. The depositions reported in this paper were carried out at room temperature although some heating of the substrates occurred on interaction with the closed field plasma. The substrate used was TEC15 fluorine doped tin oxide (FTO)-coated glass supplied by NSG Pilkington ${ }^{\circledR}$.

Cadmium sulphide $(\mathrm{CdS})$ is an n-type semiconductor, with a band gap of $2.42 \mathrm{eV}$. CdS works as a window layer with $\mathrm{CdTe}$ to form the $\mathrm{p}-\mathrm{n}$ junction. In this work, $\mathrm{CdS}$ layers were deposited on TEC15 glass using magnetron sputtering at room temperature [5]. Sputter deposited CdS thin films are typically stoichiometric [8]. Figure 1 shows the SEM image of a $250 \mathrm{~nm}$ thick CdS film deposited by sputtering. The surface appears to 
be uniform, pinhole free and with a grain size in the range of $\sim 30 \mathrm{~nm}$

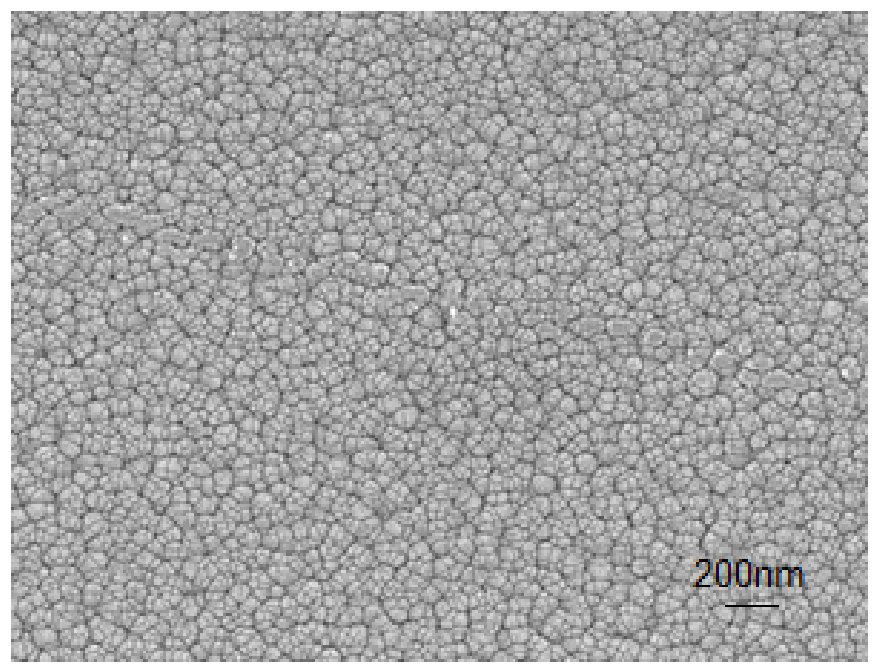

Fig. 1. SEM image of the surface of a sputter deposited CdS layer

Figure 2 shows X-Ray Diffraction (XRD) data for the CdS thin film. The spectrum corresponds to thin film CdS. The film is predominantly orientated in the $<111>$ direction [9].

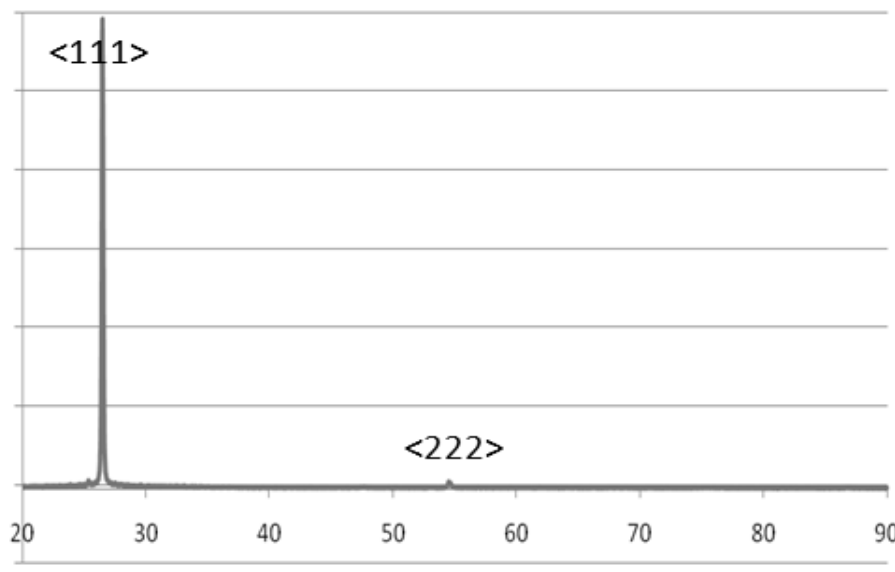

Fig. 2. XRD spectra of the sputter deposited CdS layer

CdTe is a p-type semiconductor which forms the absorber layer in the CdS/CdTe p-n junction. A CdTe thickness of $2 \mu \mathrm{m}$ results in $99 \%$ of light absorption [10], which is ideal for PV applications. A $2 \mu \mathrm{m}$ thick CdTe layer was deposited using pulsed de magnetron sputtering with the film thickness controlled by varying the deposition power and time. Figure 3 shows the surface morphology of the CdTe layer. The film growth is columnar with an average grain cross-section of $\sim 200 \mathrm{~nm}$.

Figure 4 shows the XRD spectrum from the CdTe layer. As expected for untreated sputtered $\mathrm{CdTe}$, the grain orientation is predominantly in the $<111>$ direction [10]. Both CdS and CdTe sputtered films grow in a cubic zinc-blende structure [9].

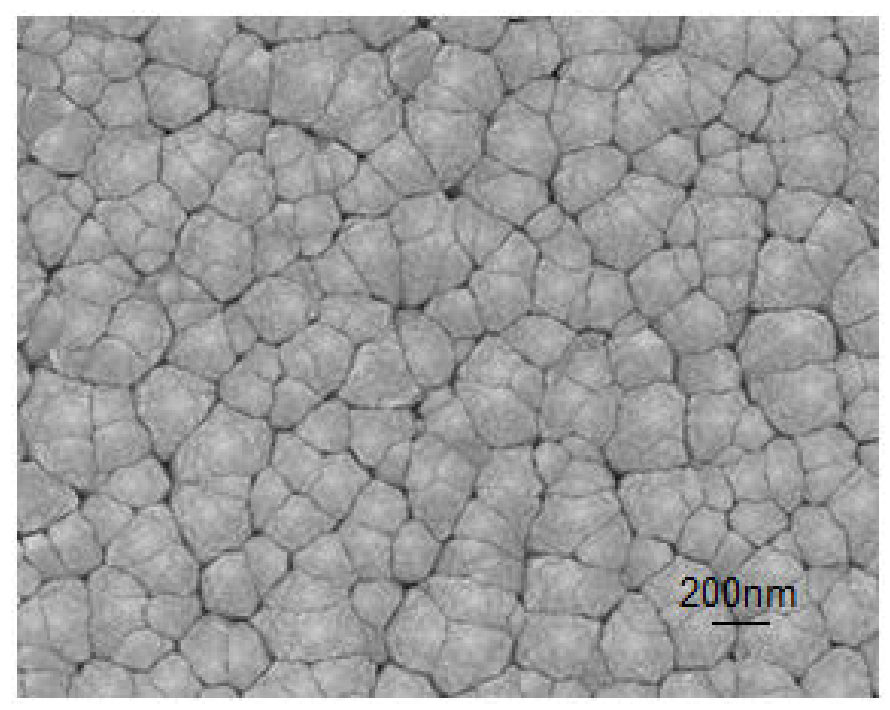

Fig. 3 SEM image of the surface of a sputter deposited CdTe thin film

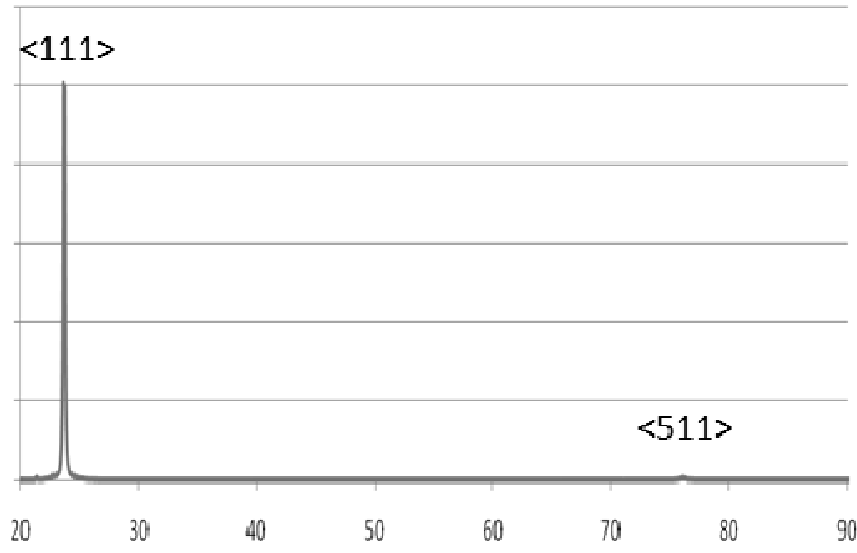

Fig. 4. XRD spectrum of the sputter deposited thin film CdTe layer

\section{B. $\mathrm{CdCl}_{2}$ Treatment}

The $\mathrm{CdCl}_{2}$ treatment can be performed using various methods, including vapour transport [11], close spaced sublimation [12], thermal evaporation [13] and a wet chemical treatment [14]. In this study, we have used the wet chemical treatment since it allowed us to easily vary the concentration of $\mathrm{CdCl}_{2}$ used. The standard procedure for full recrystallization consists of dropping the $\mathrm{CdCl}_{2}$ saturated solution $\left(2.15 \mathrm{~g} / 100 \mathrm{~g}\right.$ methanol, at $\left.20^{\circ} \mathrm{C}\right)$ on to the $\mathrm{CdTe}$ surface. This is followed by annealing at $400^{\circ} \mathrm{C}$ in air for 30 minutes. However, if the sample is treated with a very small amount of $\mathrm{CdCl}_{2}$ the re-crystallization process is incomplete and this enables us to determine where the activation process initiates. For this study low concentration solutions $(0.06 \%$ and $0.03 \%$ of saturated $\mathrm{CdCl}_{2}$ in methanol) were used to treat the CdTe surface which was then subsequently annealed. 


\section{Characterization}

A combination of microscopy techniques were employed to perform a comprehensive microstructural analysis of the untreated, treated and dilute treated samples.

A Leo 1530VP Field Emission Gun Scanning Electron Microscope FEG-SEM was used to obtain a cross-section view of the thin film CdTe multilayer stack. A dual beam FEI Nova 600 Nanolab was employed to prepare the TEM samples. TEM was carried out using a Jeol 2000FX with an integrated camera above the phosphor screen to obtain digital images. The TEM technique provides morphological analysis of grain structure across the whole multilayer thin film CdTe device.

A Tecnai Osiris ${ }^{\mathrm{TM}}$ TEM was used to provide chemical mapping for cadmium, sulphur, tellurium, chlorine and oxygen presence in the fully re-crystallized CdTe. This system is a fully digital, high-performance $200 \mathrm{kV} \mathrm{S} / \mathrm{TEM}$ system with a high sensitivity for light elements. EDS chemical maps were obtained using $\sim 1 \mathrm{nA}$ beam current for a total acquisition time of 300 seconds; the analyzed area was $800 \times 800$ pix $^{2}$, obtained with $500 \mu$ s dwell time and multiple frames.

\section{RESULTS}

\section{A. $\mathrm{CdCl}_{2}$ Treatment Of Sputtered CdS/CdTe Cells}

The SEM image of the as-deposited CdTe sample reveals a heavily columnar structure, as shown in Figure 5. The single grains, about $200 \mathrm{~nm}$ in diameter, extend through the whole thickness of the film, which confirms the high orientation in the $<111>$ direction observed by XRD measurements (Figure 4).

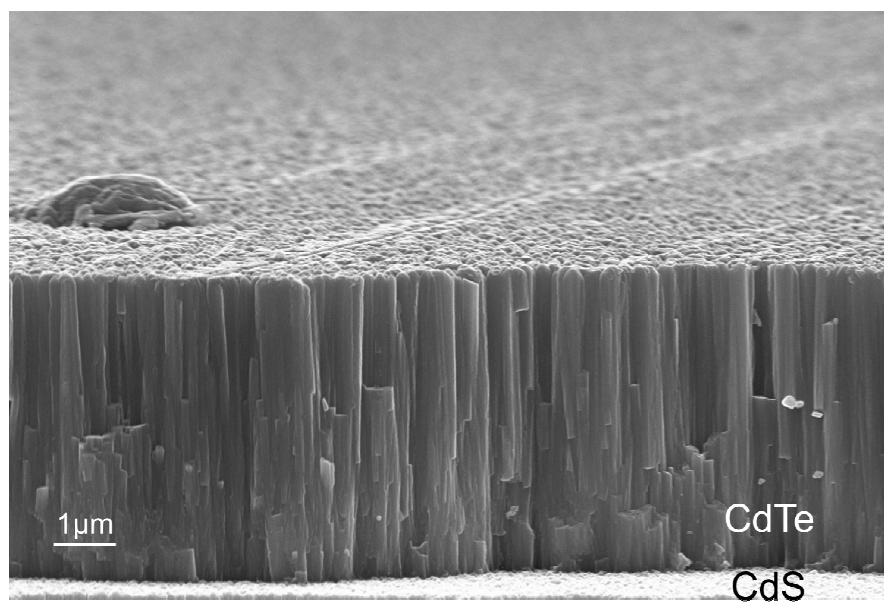

Fig. 5. SEM cross section of an untreated CdS/CdTe cell deposited using pulsed dc magnetron sputtering.
An SEM cross section of a $\mathrm{CdCl}_{2}$ treated cell is shown in Figure 6. The standard $\mathrm{CdCl}_{2}$ procedure has a dramatic effect on the CdTe thin film morphology. The grains appear to coalesce to form much larger grains which also lose their columnar appearance. The thin film now contains numerous voids possibly due to stress in the as deposited thin film. The orientation of the film is now more random, with an increase in the intensity of $<220>,<311>$ and $<331>$ peaks, from XRD measurements, shown in Figure 7.

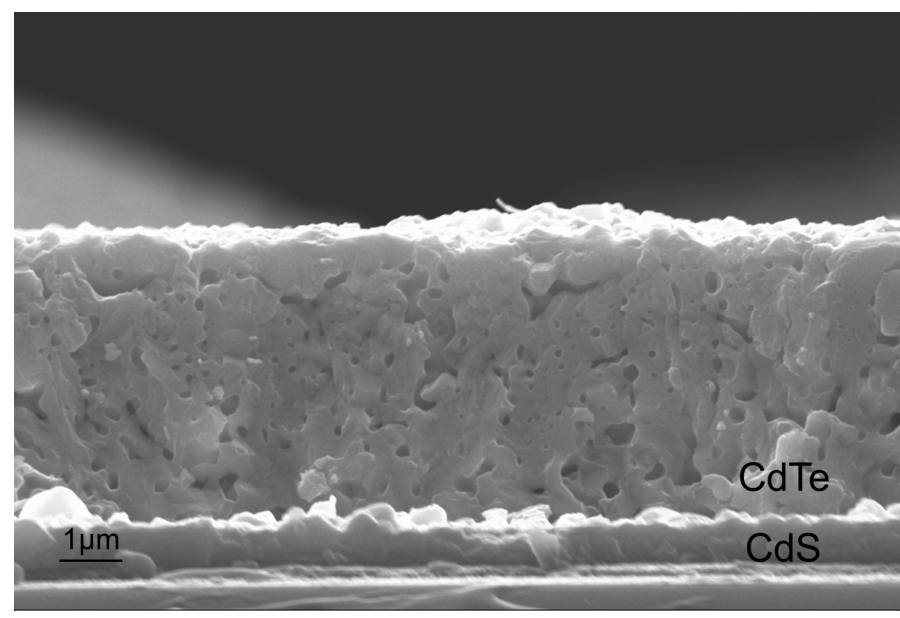

Fig. 6. SEM cross section of $\mathrm{CdCl}_{2}$ treated $\mathrm{CdS} / \mathrm{CdTe}$ cell deposited using pulsed dc magnetron sputtering.

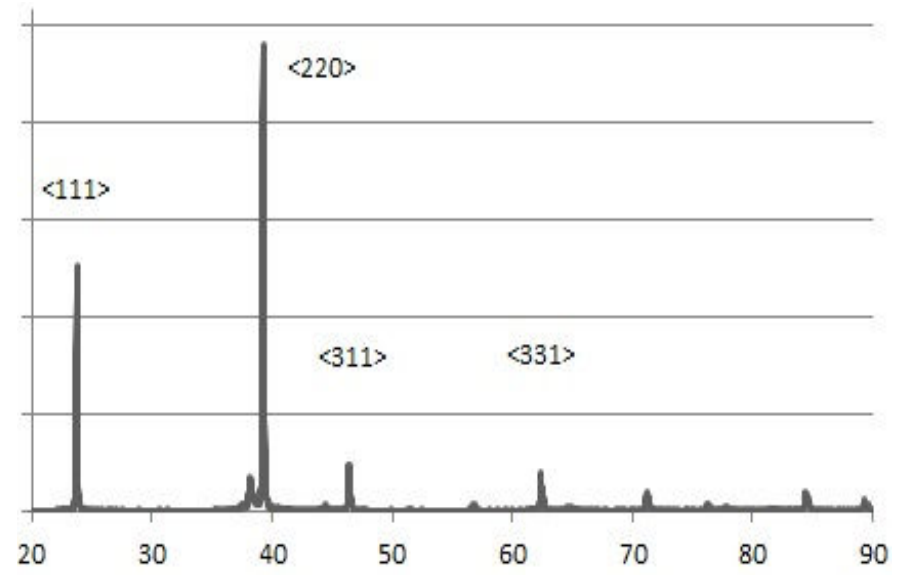

Fig. 7. XRD spectrum of fully re-crystallized sputter deposited $\mathrm{CdS} / \mathrm{CdTe}$ multistack.

EDS chemical mapping was used to image a fully recrystallized $\mathrm{CdS} / \mathrm{CdTe}$ cross section at the device junction. Chemical maps were obtained by scanning an area of the prepared TEM sample. The STEM-HAADF image of this area is showed in Figure 8. 


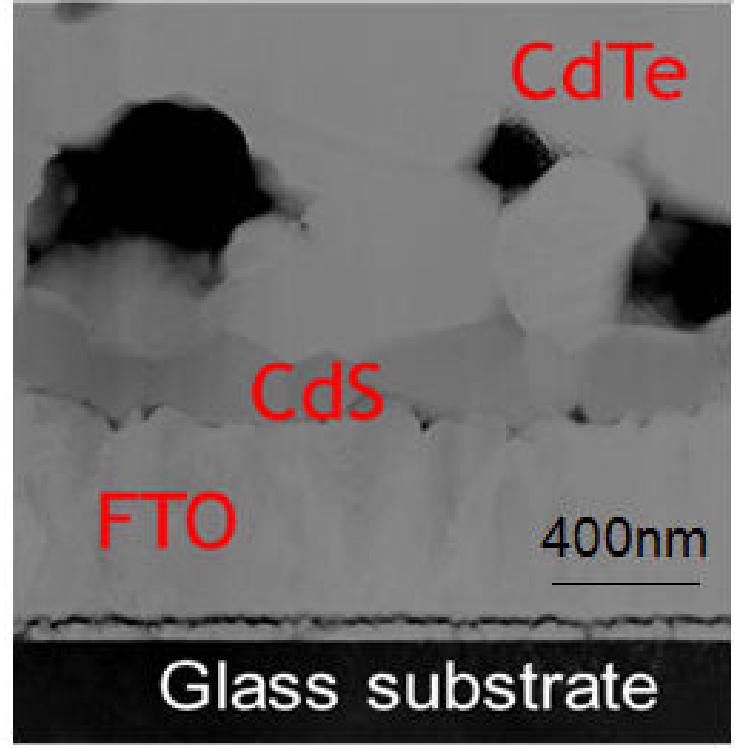

Fig. 8. STEM-HAADF image of fully treated $\mathrm{CdS} / \mathrm{CdTe}$ cell deposited using pulsed dc magnetron sputtering.

Chemical maps show the presence of elements distributed in the analysed area. Figure 9 shows images for maps of cadmium, sulphur and tellurium.
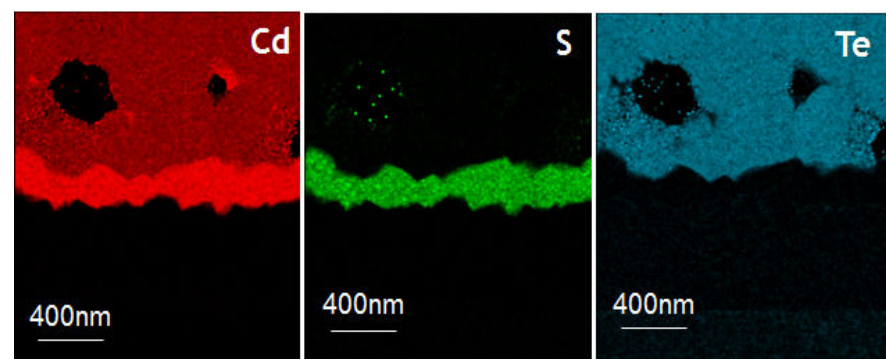

Fig. 9. EDS chemical mapping for cadmium, sulphur and tellurium for the sample area shown in Fig. 8
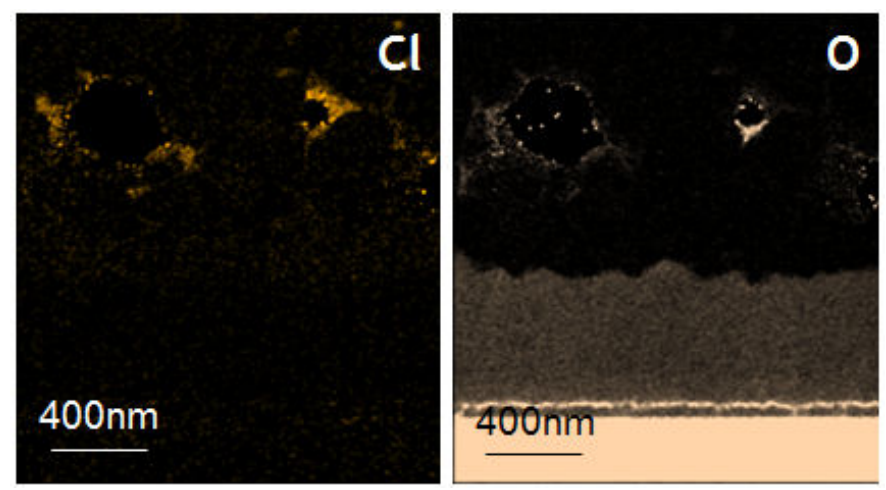

Fig. 10. EDS chemical mapping for chlorine and oxygen for the sample area shown in Fig. 8

The cadmium signal corresponds to both the CdS and CdTe layers. The sulphur and tellurium images correspond to the $\mathrm{CdS}$ and CdTe layers respectively. A sulphur signal is not detected in the $\mathrm{CdTe}$, whilst a tellurium signal is not present in the CdS layer. This may be due to the low deposition temperature used to deposit the CdTe. For high deposition temperatures (usually above $500^{\circ} \mathrm{C}$ ) inter-diffusion has been reported with the formation of $\mathrm{CdS}_{1-\mathrm{x}} \mathrm{Te}_{\mathrm{x}}$ for an oxygen deficient atmosphere [15]. However, the levels of interdiffusion may simply be below the EDS detection limits and further analysis is needed to fully investigate the inter-mixing of the layers before and after the $\mathrm{CdCl}_{2}$ treatment.

Figure 10 shows the chemical mapping for chlorine and oxygen, introduced during the $\mathrm{CdCl}_{2}$ treatment. Both elements segregate in to large voids and in to the grain boundaries. Oxygen is also present in the FTO layer as well as the glass substrate.

\section{B. Initiation $\mathrm{OfCdCl}$ Treatment}

Thin film CdS/CdTe samples were then treated with low concentration solutions: $0.06 \%$ and $0.03 \%$ of $\mathrm{CdCl}_{2}$ saturated solution in methanol and then annealed at $400^{\circ} \mathrm{C}$ for 30 minutes.

An SEM cross sectional image of a $0.06 \% \mathrm{CdCl}_{2}$ saturated solution treated sample is shown in Figure 11. In this case the process is incomplete and the CdTe layer appears to be only partially re-crystallized. Some grains towards the interface have started to coalesce to form larger grains, whilst CdTe towards the surface remains largely unaffected. Since the $\mathrm{CdCl}_{2}$ solution was dropped directly onto the CdTe surface, it would be intuitive to expect the surface as the likely location for the re-crystallization process to begin. Surprisingly, Figure 11 shows that the process initiates at the $\mathrm{CdS} / \mathrm{CdTe}$ interface whilst the CdTe surface retains its as-deposited morphology.

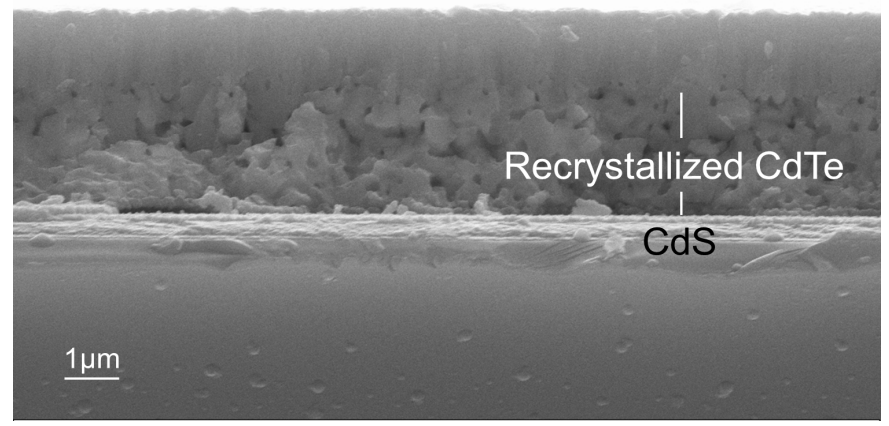

Fig. 11. SEM cross section of the CdS/CdTe magnetron sputtered cell treated with dilute $0.06 \%$ of $\mathrm{CdCl}_{2}$ saturated solution.

TEM analysis was also used to study the grain morphology. TEM images show the different layers of the device structure and they also provide information on the presence of defects inside the grains. In order to study how the $\mathrm{CdCl}_{2}$ process is initiated, it is possible to use TEM images to both identify any change in the grain size/shape and the presence of stacking faults inside the grains. Removal of stacking faults has been found to be a key feature of the re-crystallization of the structure [4]. 


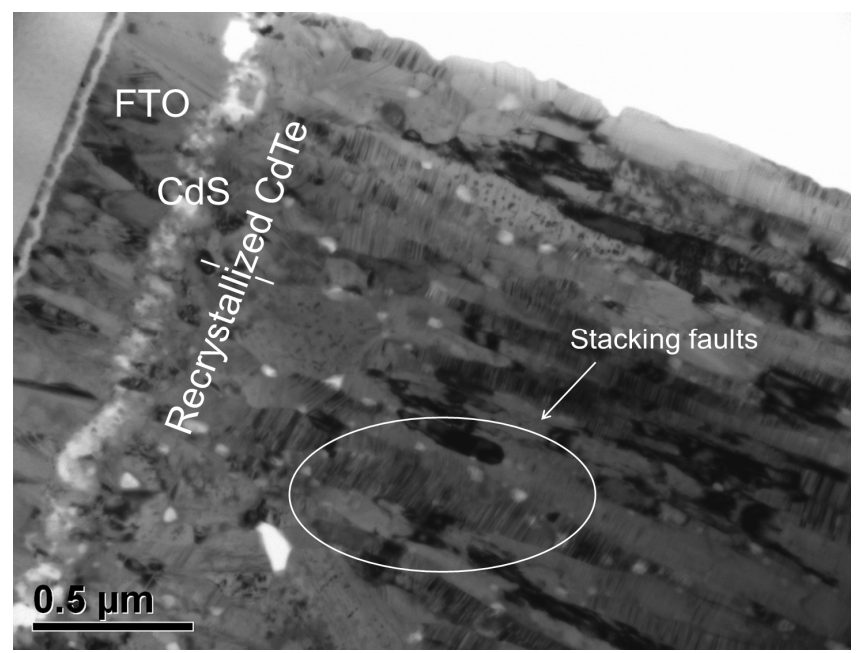

Fig. 12. This TEM image shows re-crystallization starting at the $\mathrm{CdS} / \mathrm{CdTe}$ interface. The sputtered cell was treated with a dilute $0.03 \% \mathrm{CdCl}_{2}$ of saturated solution in methanol.

A TEM image of the magnetron sputtered $\mathrm{CdS} / \mathrm{CdTe}$ cell treated with $0.03 \% \mathrm{CdCl}_{2}$ saturated solution in methanol is shown in Figure 12. This image clearly shows that the recrystallization initiates at the interface between $\mathrm{CdS}$ and CdTe. This confirms the observation revealed in the SEM cross section image. In the recrystallized area near the interface, the grains are rounder in shape and they appear to have coalesced. The grains located away from the interface remain columnar. In addition, the rounded grains near the interface do not contain stacking faults, which appear as lines perpendicular to the growth of the grain. In contrast, the nonrecrystallized columnar grains, which extend up to the film surface, contain these defects.

\section{CONCLUSIONS}

As deposited thin film CdTe using pulsed dc magnetron sputtering is highly columnar with grains typically $200 \mathrm{~nm}$ in diameter with a strong orientation into the $<111>$ direction. We have treated these films with both a standard full $\mathrm{CdCl}_{2}$ treatment and a highly dilute $\mathrm{CdCl}_{2}$ wet chemical treatment. The standard procedure results in fully re-crystallized $\mathrm{CdTe}$ with grain coalescence to form larger grains and more randomly orientated.

Using the dilute $\mathrm{CdCl}_{2}$ treatment, both SEM cross section and TEM images reveal that a partial re-crystallization occurs. The CdTe grains close to the CdS interface are more round and stacking fault defects are removed. In contrast, the material close to the treated CdTe surface is still columnar and still contains a high density of stacking faults. This is an important observation since it implies that the recrystallization process does not initiate at the treated surface but starts at the CdS/CdTe interface in sputtered films. This supports previous measurements using XPS in depth profiling mode which revealed that the concentration of chlorine was highest at the interface [3]. Further work is now required on thin film CdTe cells deposited using close spaced sublimation to confirm that this observation is not a process limited to cells deposited using magnetron sputtering.

\section{REFERENCES}

[1] US Department of Energy, "2010 Solar Technologies Market Report," 2011.

[2] First Solar, "First Solar CdTe module record efficiency," 2012. [Online]. Available:

http://investor.firstsolar.com/releasedetail.cfm?release $\underline{\mathrm{id}=755244}$

[3] A. Abbas, G.D. West, P. Rowley, J.W. Bowers, P.M. Kaminski, B. Maniscalco, J.M. Walls, W.S. Sampath and K.L. Barth "The Effect of Cadmium Chloride Treatment on Close Spaced Sublimated Cadmium Telluride Thin Film Solar Cells," IEEE Journal of Photovoltaics in press, 2013.

[4] J.M. Walls, A. Abbas, G. D. West, J.W. Bowers, P.J.M. Isherwood, P.M. Kaminski, B. Maniscalco, K. Barricklow, W.S. Sampath and K.L. Barth, "The Effect of Annealing Treatments on Close Spaced Sublimated Cadmium Telluride Thin Film Solar Cells," MRS Online Proceedings Library, Volume 1493, mrsf12-1493-e04-02, January 2012.

[5] A. Abbas, J.W. Bowers, B. Maniscalco, S. Moh, G.D West, P.N. Rowley, H.M Upadhyaya and J.M. Walls, "Characterization of Thin Film CdTe photovoltaic materials deposited by high plasma density magnetron sputtering," MRS Online Proceedings Library, Vol 1323, mrss11-1323c06-08, Jan 2011.

[6] D. G. Teer, US patent number 5,554,519, 1991.

[7] J. M. Walls and D. R. Gibson 'High Throughput Optical Coating' Photonics Spectra 42, pp56-58, 2008.

[8] D. B. Fraser and H. Melchior, Sputter-deposited CdS films with high photoconductivity through film thickness, J. Appl. Phys. 43, 3120, 1972.

[9] 00-001-0647 Power Diffraction File (PDF) database.

[10] A.R. Flores, R. Castro-Rodriguez, J.L. Pena, N. Romeo, A. Bosio, "Characterization of CdTe films with in situ $\mathrm{CdCl}_{2}$ treatment grown by a simple vapor phase deposition technique", Applied Surface Science vol. 255, pp. 70127016, 2009.

[11] B.E. McCandless and W.A. Buchanan, "High throughput processing of $\mathrm{CdTe} / \mathrm{CdS}$ solar cells with thin absorber layers", 33rd IEEE Photovoltaic Specialists Conference, pp. 1-6, May 2008.

[12] V. Manivannan, R. Enzenroth, K.L. Barth, S. Kohli, P. Mccurdy, and W.S. Sampath, "Microstructural features of cadmium telluride photovoltaic thin film devices," Thin Solid Films, vol. 516, no. 6, pp. 1209-1213, Jan. 2008.

[13] G. Khrypunov, A. Romeo, F. Kurdesau, D. Batzner, H. Zogg, and A. Tiwari, "Recent developments in evaporated CdTe solar cells," Solar Energy Materials and Solar Cells, vol. 90, no. 6, pp. 664-677, Apr. 2006.

[14] C.L. Ferreira and J. Quadros, "Fabrication of $\mathrm{TCO} / \mathrm{CdS} / \mathrm{CdTe} / \mathrm{Au}$ solar cells using different $\mathrm{CdCl}_{2}$ treatments", 33rd IEEE Photovoltaic Specialists Conference, pp. 1-4, 2008.

[15] C.S. Ferekides, D. Marinskiy, V. Viswanathan, B. Tetali, V. Palekis, P. Salvaraj, D.L. Morel, "High efficiency CSS CdTe solar cells", Thin Solid Films, 361-362, pp. 520-526, 2000 . 